\title{
IL-33/ST2 promotes the malignant progression of gastric cancer via the MAPK pathway
}

\author{
NING HUANG ${ }^{1}, \mathrm{XING}_{\mathrm{CUI}}{ }^{2}, \mathrm{WEN} \mathrm{LI}^{1}, \mathrm{CHUNLAI} \mathrm{ZHANG}^{1}$, LIQING LIU ${ }^{1}$ and JINXING LI \\ Departments of ${ }^{1}$ Clinical Laboratory and ${ }^{2}$ Hematology, Affiliated Hospital of Shandong University \\ of Traditional Chinese Medicine, Jinan, Shandong 250012, P.R. China
}

Received March 20, 2020; Accepted December 2, 2020

DOI: $10.3892 / \mathrm{mmr} .2021 .12000$

\begin{abstract}
Gastric cancer (GC) remains one of the commonest malignant tumors and the second leading cause of cancer-related deaths worldwide. IL-33 is highly expressed in tumor tissues and serum of patients with GC. However, the function of the IL-33 and IL-33 receptor ST2 in the malignant progression of GC is yet to be elucidated. The present study aimed to explore the effect of the IL-33/ST2 axis on the biological functions of GC cells. The expression of ST2 in GC tissues was measured by immunohistochemistry. GC cell lines (AGS and MKN45) were treated with IL-33, and the expression of ST2 was downregulated by using specific siRNA. The effects of the IL-33/ST2 axis on cell proliferation, migration, invasion, cell cycle and apoptosis was detected by CCK8, Transwell, wound healing, flow cytometry and western blotting assays. The present study found that ST2 was highly expressed in GC tissues compared with normal tissues. IL-33 promoted the proliferation and cell cycle progression of GC cells, and upregulated the expression levels of CDK4, CDK6 and cyclin D1. Furthermore, IL-33 inhibited the apoptosis of GC cells and regulated the expression of apoptosis-associated proteins. In addition, IL-33 stimulated the invasion and migration of GC cells. However, the transfection of ST2 small interfering (si)RNA attenuated the effects of IL-33. Finally, IL-33 stimulation increased the phosphorylation levels of ERK1/2, JNK and p38. The transfection of ST2 siRNA could significantly inhibit the IL-33-induced ERK1/2, JNK and p38 activation. In conclusion, it was found that ST2 was highly expressed in GC tissues. IL-33/ST2 promoted the malignant progression of GC cells by inducing the activation of ERK1/2, JNK and p38.
\end{abstract}

Correspondence to: Professor Ning Huang, Department of Clinical Laboratory, Affiliated Hospital of Shandong University of Traditional Chinese Medicine, 16369 Jingshi Road, Jinan, Shandong 250012, P.R. China

E-mail: hningszy@163.com

Key words: IL-33, ST2, gastric cancer, MAPK

\section{Introduction}

At present, gastric cancer (GC) is still one of the most common malignant tumors (1) and the second leading cause of cancer-related deaths worldwide (2). Although the incidence rates in Western countries have begun to decline, rates remain high in Asian countries (3). The incidence of GC in China accounts for $>40 \%$ of the global incidence rate, and $>1.6$ million individuals succumb to GC each year (4). Immune dysfunction is considered to be involved in the occurrence and progression of tumors (5). A number of pro-inflammatory factors, such as IL-6, IL-10 and IL-8, have been found to be significantly elevated in tumor tissues and serum, and are usually associated with poor prognosis (6-8).

As a member of the IL-1 family, IL-33 is originally produced as a $30 \mathrm{kDa}$ precursor protein, which is then cleaved by caspase- 1 into a $18 \mathrm{kDa}$ mature and secreted form (9). IL-33 has been reported to be related to inflammation, infectious diseases and tumor progression (10). Elevated serum levels of IL-33 have been demonstrated in numerous types of cancer, including breast (11) and hepatocellular cancer (12). However, it has been reported that in patients with multiple myeloma, decreased plasma levels of IL-33 are associated with more advanced stages of the disease (13). Serum IL-33 levels are significantly elevated in patients with GC, and elevated serum IL-33 levels are related to infiltration, distant metastasis and advanced stages $(14,15)$. In GC tissues, IL-33 expression is also significantly increased and associated with the infiltration depth, but it does not seem to be significantly associated with the overall survival rate of patients with GC (16). ST2 is a recognized IL-33 receptor. Compared with IL-33, the role of ST2 in cancer has rarely been investigated.

In the present study, the effects of the IL-33/ST2 axis on the biological functions of GC cells were examined. It was found that the IL-33/ST2 axis contributed to GC cell proliferation, cell cycle progression, apoptosis inhibition, invasion and migration by inducing the activation of ERK1/2, JNK and p38.

\section{Materials and methods}

Patients and tissue samples. A total of 75 patients who were diagnosed and underwent surgical resection of gastric carcinoma at the Affiliated Hospital of Shandong University of 
Traditional Chinese Medicine (Jinan, China) were enrolled, and GC tissue specimens and adjacent normal tissue specimens $(<3 \mathrm{~cm})$ were collected. The tissue samples were immediately frozen in liquid nitrogen and stored in a refrigerator at $-80^{\circ} \mathrm{C}$. None of the patients included in this study had received chemotherapy or radiotherapy before surgery, and all patients signed written informed consent. Patients diagnosed with rheumatic diseases, acute infections or other types of cancer were also excluded. The study was approved by the Ethics Committee of the Affiliated Hospital of Shandong University of Traditional Chinese Medicine.

Immunohistochemical analysis. The tissues were fixed in $10 \%$ formalin at $4^{\circ} \mathrm{C}$ for $24 \mathrm{~h}$, and then embedded in paraffin. The tissue samples were cut into $4 \mu \mathrm{m}$ slices, and the paraffin-embedded slices were deparaffinized in detergent and rehydrated in alcohol. Sodium citrate buffer ( $\mathrm{pH}$ 6.0) was used for antigen retrieval. After blocking with 5\% goat serum (Thermo Fisher Scientific Inc.) at room temperature for $1 \mathrm{~h}$, the slides were incubated with anti-ST2 (1:100; cat. no. ab233433, Abcam) for $1 \mathrm{~h}$ at room temperature, followed by incubation with the horseradish peroxidase (HRP)-labeled goat anti-mouse/rabbit IgG polymer (1:5,000; cat. no. 160101405L; Fuzhou Maixin Biotech Co., Ltd.) for $1 \mathrm{~h}$ at room temperature. The enhanced DAB chromogenic kit (cat. no. 1705252031; Fuzhou Maixin Biotech Co., Ltd.) was used for color development. After counterstaining with hematoxylin at room temperature for $5 \mathrm{~min}$, it was dehydrated in gradient ethanol and fixed with neutral resin. Then, slides were observed and imaged under a light microscope. The ST2 immunostaining score was the sum of the staining intensity score and the positive staining cell rate score. The staining intensity was scored as follows: i) 0 , no staining; ii) 1 , weak staining; iii) 2 , moderate staining; and iv) 3 , strong staining. The positive staining cell rate was scored as follows: i) $0,0-5 \%$; ii) $1,5-25 \%$; iii) $2,26-50 \%$; iv) $3,51-75 \%$; and v) $4,>75 \%$. A score $<2$ points was considered as ST2 low expression, $>3$ points as ST2 high expression.

Cell culture and transfection. Human GC cell lines, AGS and MKN45, were obtained from The Cell Bank of Type Culture Collection of The Chinese Academy of Sciences and $1 \times 10^{5}$ cells were cultured in Dulbecco's modified Eagle's medium (DMEM; Hyclone; Cytiva) containing 10\% FBS (Gibco; Thermo Fisher Scientific, Inc.), $100 \mathrm{U} / \mathrm{ml}$ penicillin and $0.1 \mathrm{mg} / \mathrm{ml}$ streptomycin (Sigma-Aldrich; Merck KGaA) in 6-well plates. Cells were maintained in a humidified incubator at $37^{\circ} \mathrm{C}$ with $5 \% \mathrm{CO}_{2}$. AGS and MKN45 cells were incubated with IL-33 at a final concentration of $10 \mathrm{ng} / \mathrm{ml}$.

Cells in the logarithmic growth phase were transfected with control small interfering (si)RNA (NC; 5'-AAUUCUCCGAAC GUGUCACGU-3') or ST2 siRNA (siST2; 5'-CCAGAAAGG CCUCUAGUUUUU-3') $(6 \mu \mathrm{g})$ using Lipofectamine ${ }^{\circledR} 2000$ (Invitrogen; Thermo Fisher Scientific, Inc.) at $37^{\circ} \mathrm{C}$. After $6 \mathrm{~h}$ of transfection, the medium was changed and the cells were cultured for $24 \mathrm{~h}$. Then, the subsequent experiments were performed. The ST2 siRNA and negative control (NC) siRNA were designed and obtained from Shanghai GenePharma Co., Ltd.
Reverse transcription-quantitative (RT-q) PCR. Total RNA from the cells was extracted using the Ultrapure RNA extraction kit (CoWin Biosciences), and reverse transcribed into cDNA using the HiFiScript cDNA Synthesis kit (CoWin Biosciences) at $37^{\circ} \mathrm{C}$ for $30 \mathrm{~min}$. RT-qPCR was performed with the Magic SYBR mixture (CoWin Biosciences) and a StepOne $^{\mathrm{TM}}$ Real-Time PCR System (Applied Biosystems; Thermo Fisher Scientific, Inc.). The cycling conditions were: Denaturation at $95^{\circ} \mathrm{C}$ for $5 \mathrm{~min}$, followed by 40 cycles of $95^{\circ} \mathrm{C}$ for $30 \mathrm{sec}, 60^{\circ} \mathrm{C}$ for $45 \mathrm{sec}$ and $72^{\circ} \mathrm{C}$ for $30 \mathrm{sec}$. The ST2 siRNA was designed and obtained from Invitrogen (Thermo Fisher Scientific, Inc.) with the sequence 5'-CCAGAAAGGCCUCUAGUUUUU-3'. The relative expression of ST2 was quantified using the $2^{-\Delta \Delta \mathrm{Cq}}$ method (17) and normalized to the expression of $\beta$-actin.

Western blotting. Total protein in cells was extracted using RIPA buffer containing protease cocktail inhibitor I (Calbiochem; Merck KGaA). Protein (15 $\mu \mathrm{g}$ ) was separated via SDS-PAGE on a $10 \%$ gel, and subsequently electroblotted onto a PVDF membrane. After blocking with $5 \%$ non-fat milk for $1 \mathrm{~h}$ at room temperature, the PVDF membrane was incubated with the primary antibodies against ST2 (1:1,000; cat. no. ab233433, Abcam), CDK4 (1:2,000; cat. no. ab108357; Abcam), CDK6 (1:2,000; cat. no. ab124821; Abcam), cyclin D1 (1:2,000; cat. no. ab134175; Abcam), Bcl-2 (1:2,000; 60178-1-Ig; ProteinTech Group Inc.), Bax (1:1,000; 50599-2-Ig; ProteinTech Group Inc.), caspase-3 (1:1,000; 19677-1-AP; ProteinTech Group Inc.); ERK (1:1,000; cat. no. ab32537; Abcam), p-ERK (1:1,000; cat. no. ab192591; Abcam), JNK (1:1,000; cat. no. ab179461; Abcam), p-JNK (1:1,000; cat. no. ab124956; Abcam), p38 (1:1,000; cat. no. ab170099; Abcam), p-p38 (1:1,000; cat. no. ab178867; Abcam), and GAPDH (1:5,000; cat. no. ab8245; Abcam) at $4^{\circ} \mathrm{C}$ overnight, and then incubated with the anti-rabbit $\operatorname{IgG}(1: 2,000$; cat. no. GTX300119; GeneTex, Inc.) or anti-mouse IgG (1:2,000; cat. no. GTX300120; GeneTex, Inc.) secondary antibodies for $1 \mathrm{~h}$ at room temperature. The protein bands were visualized using a Pierce ${ }^{\mathrm{TM}}$ ECL Western Blotting Substrate (Thermo Fisher Scientific, Inc.). Bands were semi-quantified using ImageJ software v1.8.0 (National Institutes of Health). GAPDH was used as the internal reference.

Cell Counting Kit-8 (CCK-8) assay. Cell proliferation was assessed using a CCK-8 assay. A total of 2,000 cells were seeded into each well of a 96-well plate. CCK-8 solution (10 $\mu$ l) (Beijing Solarbio Science and Technology Co., Ltd.) was added into each well at different times points $(0,24,48$ and $72 \mathrm{~h}$ ) and cells were incubated for $2 \mathrm{~h}$ at $37^{\circ} \mathrm{C}$. The absorbance at $450 \mathrm{~nm}$ was measured using a microplate reader.

Cell cycle analysis using flow cytometry. After $48 \mathrm{~h}$ of treatment, the cells were trypsinized with EDTA-free trypsin and resuspended in cold PBS. Then, the cells were fixed in cold $70 \%$ ethanol at $-20^{\circ} \mathrm{C}$ for $24 \mathrm{~h}$. The fixed cells were incubated with RNase A at room temperature for $30 \mathrm{~min}$, and stained with propidium iodide for another $30 \mathrm{~min}$ at room temperature in the dark using Cell Cycle Analysis Kit (Beyotime 
Institute of Biotechnology). Cell cycle progression was immediately measured using a FACSCalibur Flow Cytometer (BD Biosciences), and analyzed using FCS Express 4 software (De Novo Software).

Apoptosis analysis using flow cytometry. Cells were stained with $5 \mu$ l Annexin V-FITC (BD Biosciences) at room temperature for $5 \mathrm{~min}$. Then $10 \mu \mathrm{l}$ propidium iodide (PI) and $400 \mu \mathrm{l}$ PBS buffer were added to the cell suspension. The early and late apoptosis was detected using a BD FACSCanto ${ }^{\mathrm{TM}}$ II (BD Biosciences) flow cytometer. Data were collected and analyzed using FlowJo software v.4.5 (FlowJo LLC).

Invasion assay. The Transwell chambers (BD Biosciences) coated with Matrigel at $37^{\circ} \mathrm{C}$ for $4 \mathrm{~h}$ were used to measure cell invasion. Cells transfected with control siRNA or ST2 siRNA for $12 \mathrm{~h}$ were digested and resuspended into cell suspension at a density of $1 \times 10^{6}$ cells $/ \mathrm{ml}$. Cell suspension (200 $\mu \mathrm{l})$ with serum-free medium was loaded into the upper chamber. IL-33 was added or not added to the upper chamber with a final concentration of $10 \mathrm{ng} / \mathrm{ml}$ at $37^{\circ} \mathrm{C}$ for $24 \mathrm{~h}$. The lower chambers were filled with $600 \mu 1$ DMEM containing $10 \% \mathrm{FBS}$ to induce cell invasion. After incubation at $37^{\circ} \mathrm{C}$ for $24 \mathrm{~h}$, cells on the upper surface of the chambers were removed with a cotton swap. The invading cells on the lower surface of the chambers were fixed with $4 \%$ paraformaldehyde for $30 \mathrm{~min}$ at room temperature and stained with $0.1 \%$ crystal violet at room temperature for $10 \mathrm{~min}$. The number of cells was counted under a light microscope (magnification, x200, Nikon TE2000; Nikon Corporation).

Migration assays. A wound healing assay was performed to evaluate the migratory ability of GC cells. AGS and MKN45 cells were grown to $95 \%$ confluence in 6-well plates. A sterile plastic tip was used to create the wound. After washing with PBS, the cells were cultured for $48 \mathrm{~h}$ in serum-free medium. Images were taken using a light microscope (magnification, x100). The average of five random widths of each wound was measured for quantitation.

Statistical analysis. All data analysis was performed as the mean \pm SD using GraphPad software Prism 8 (GraphPad Software, Inc.) and SPSS 13.0 (SPSS, Inc.). All experiments were repeated at least three times. The differences between two groups were analyzed using a Student's t-test, and the statistical differences among multiple groups were assessed by one-way analysis of variance followed by Tukey's post hoc test. The data in Table I were analyzed by the $\chi^{2}$ test and those in Table II were analyzed by the Fishers test. $\mathrm{P}<0.05$ was considered to indicate a statistically significant difference.

\section{Results}

ST2 is highly expressed in GC tissues. First, the expression of ST2 in GC tissues and adjacent normal tissue was examined by immunohistochemical analysis. As shown in Fig. 1A and Table I, ST2 was expression was significantly higher in GC tissues compared with normal tissues. It was found that the expression of ST2 had no association with the sex, age, tumor size and pathological grade of patients with GC (Table II).
Table I. ST2 expression in GC compared with para-carcinoma tissues.

\begin{tabular}{lllll}
\hline & & \multicolumn{2}{c}{ ST2 expression } & \\
\cline { 3 - 4 } Group & $\mathrm{n}$ & Low, n (\%) & High, n (\%) & P-value \\
\hline GC & 75 & $31(41.3)$ & $44(58.6)$ & $0.001^{\mathrm{a}}$ \\
Para-carcinoma & 75 & $52(69)$ & $23(30.6)$ & \\
\hline
\end{tabular}

${ }^{\mathrm{a}} \mathrm{P}<0.01$ vs. para-carcinoma tissues. GC, gastric cancer.

Table II. Association between ST2 expression and the clinicopathological parameters of GC.

\begin{tabular}{lcccc}
\hline & & \multicolumn{2}{c}{ ST2 expression } & \\
\cline { 3 - 4 } $\begin{array}{l}\text { Clinicopathological } \\
\text { parameters }\end{array}$ & & $\begin{array}{c}\text { Low, } \\
\mathrm{n}(\%)\end{array}$ & $\begin{array}{c}\text { High, } \\
\mathrm{n}(\%)\end{array}$ & P-value \\
\hline Sex & $\mathrm{n}$ & & & 0.2471 \\
$\quad$ Male & 56 & $21(37.5)$ & $35(62.5)$ & \\
$\quad$ Female & 19 & $10(52.6)$ & $9(47.4)$ & \\
Age, years & & & & 0.9144 \\
$\quad<60$ & 32 & $13(40.7)$ & $19(59.3)$ & \\
$\geq 60$ & 43 & $18(42.9)$ & $25(58.1)$ & \\
Tumor diameter, cm & & & & 0.698 \\
$\quad<5$ & 31 & $12(38.7)$ & $19(61.3)$ & \\
$\geq 5$ & 44 & $19(43.2)$ & $25(56.8)$ & \\
Pathological grading & & & & 0.3496 \\
$\quad$ I-III & 49 & $19(38.8)$ & $30(61.2)$ & \\
$\quad$ III-IV & 26 & $13(50)$ & $13(50)$ &
\end{tabular}

$\mathrm{GC}$, gastric cancer.

IL-33 induces ST2 expression in GC cells. The human GC cell lines, AGS and MKN45, were selected for subsequent experiments. As shown in Fig. 1B and C, IL-33 (10 ng/ml) induced ST2 mRNA and protein expression in AGS and MKN45 cells. Under IL-33 stimulation, transfection of siST2 significantly inhibited ST2 mRNA and protein expression in AGS and MKN45 cells (Fig. 1B and C). Without the addition of IL-33, transfection of siST2 also significantly reduced the expression of ST2 (Fig. 1D). In addition, IL-33 stimulated the expression of ST2 in a dose-dependent manner (Fig. 1E).

IL-33/ST2 axis promotes GC cell proliferation by regulating the cell cycle. In order to investigate the role of IL-33 and ST2 in the biological function of GC cells, the proliferation and cell cycle of AGS and MKN45 cells were examined. As shown in Fig. 1F, IL-33 promoted the proliferation of AGS and MKN45 cells compared with the NC cells, and the promotion of IL-33 on cell proliferation was reduced by the transfection of siST2. Furthermore, IL-33 stimulation increased the ratio of $S$ phase and G2 phase cells, and decreased the ratio of G1 phase cells, 


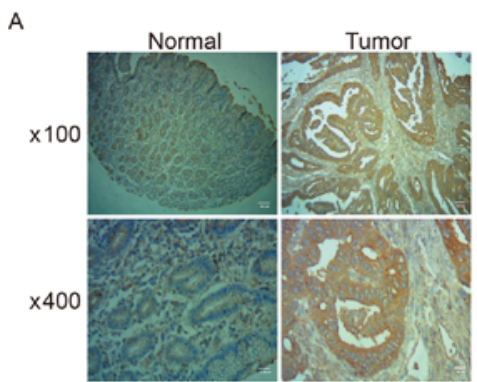

B
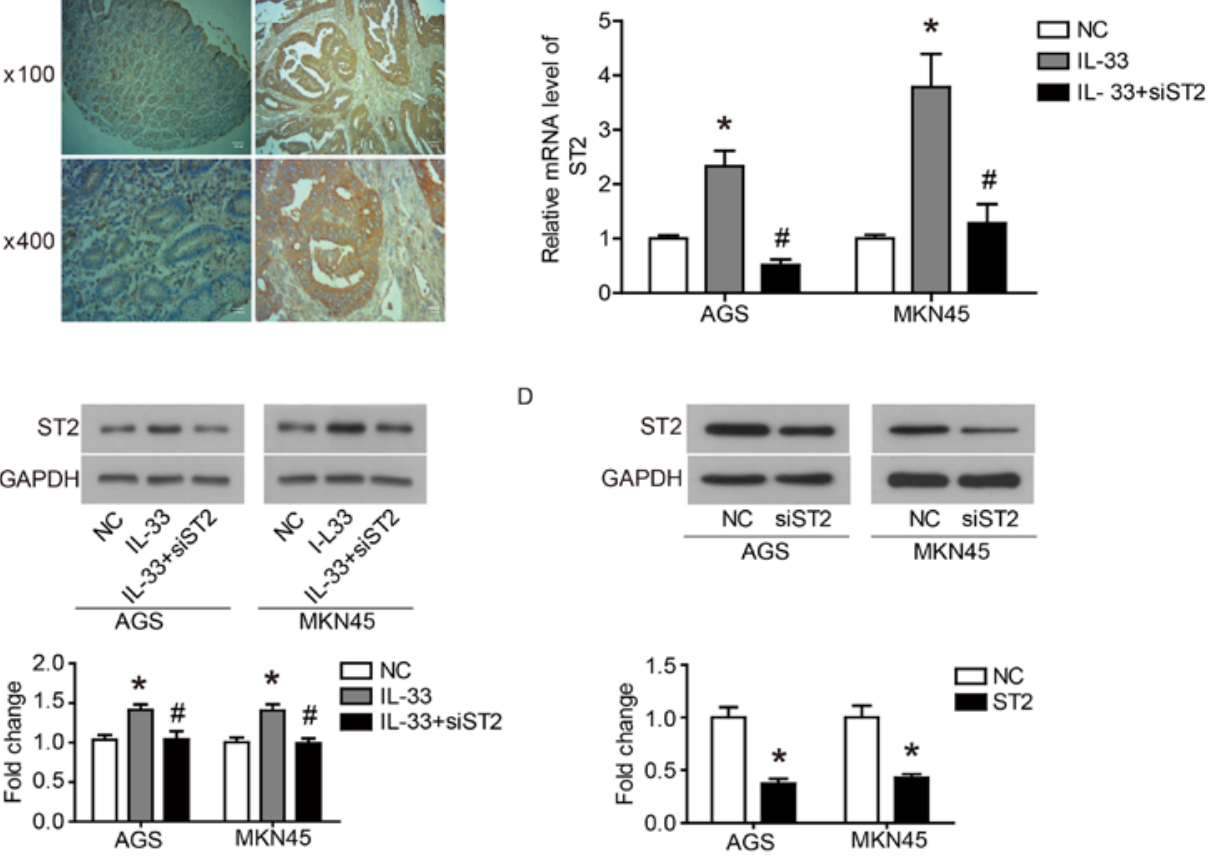

$E$
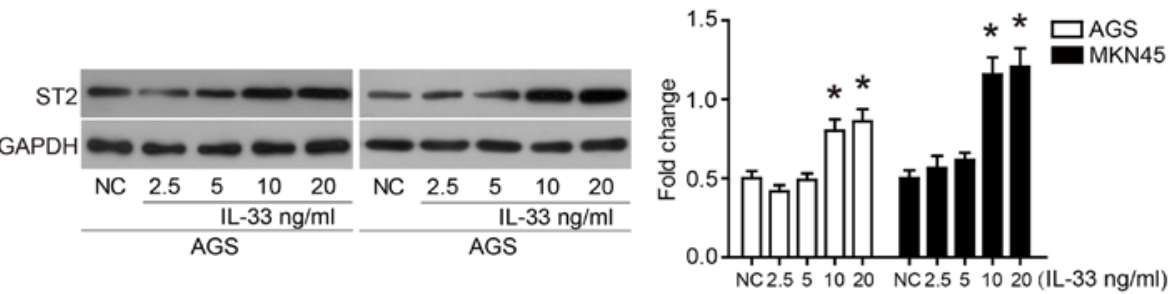

$\mathrm{F}$
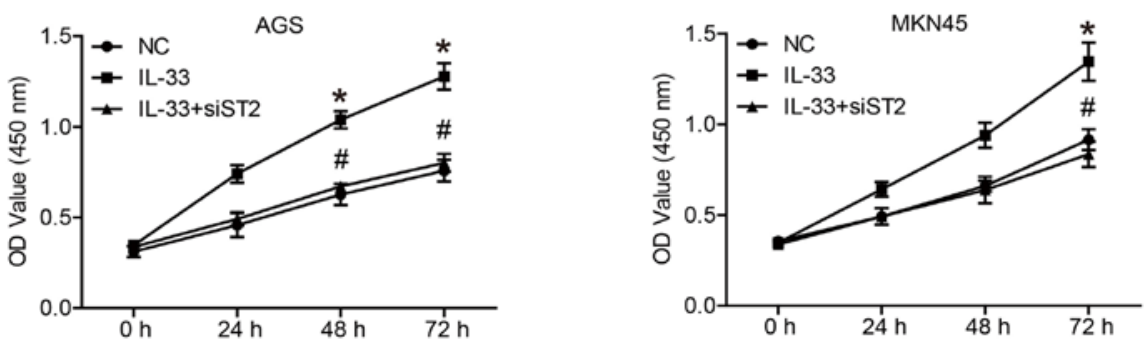

Figure 1. ST2 is highly expressed in GC tissues and IL-33/ST2 axis promotes proliferation of GC cells. (A) ST2 expression in GC tissues and adjacent normal tissues was examined by immunohistochemical analysis. Top panel magnification, x100; bottom panel magnification, x400. (B) mRNA and (C-E) protein expression levels of ST2 in AGS and MKN45 cells were detected by reverse transcription-quantitative PCR and western blotting. (F) Cell proliferation of AGS and MKN45 cells was measured using Cell Counting Kit-8 assays. Student's t-test was used for comparison between two groups, and one-way ANOVA was used for comparison among multiple groups. All experiments were performed in triplicate. " $\mathrm{P}<0.05 \mathrm{IL}-33 \mathrm{vs}$. NC; ${ }^{\#} \mathrm{P}<0.05 \mathrm{IL}-33+\mathrm{siST} 2 \mathrm{vs}$. IL-33. GC, gastric cancer; NC, negative control; si-, small interfering RNA.

which was offset by the transfection of siST2 (Fig. 2A and B). In addition, IL-33 stimulation upregulated the expression of CDK4, CDK6 and cyclin D1, which drive cell cycle progression (Fig. 2C). Transfection of siST2 reduced the regulation of IL-33 on cell cycle-associated proteins (Fig. 2C). These results indicated that the IL-33/ST2 axis promoted the proliferation of $\mathrm{GC}$ cells by regulating the cell cycle.

IL-33 inhibits GC cell apoptosis via the ST2 receptor. Furthermore, the effects of IL-33 and ST2 on GC cell apoptosis were determined using flow cytometry. As shown in Fig. 3A and B, IL-33 inhibited the apoptosis of AGS and MKN45 cells, while the transfection of siST2 counteracted the effect of IL-33 on apoptosis. In addition, IL-33 stimulation increased protein expression of $\mathrm{Bcl} 2$, and decreased the protein expression of Bax and caspase-3, which was also affected by transfection of siST2 (Fig. 3C and D). These data demonstrated that IL-33 inhibited GC cells apoptosis through the ST2 receptor.

ST2 receptor contributes to IL-33-induced GC cell invasion and migration. To clarify the role of IL-33 and ST2 in the invasion and migration of GC cells, Transwell and wound healing assays were performed. The results of the Transwell assay showed that IL-33 stimulated the invasion of AGS and 
A

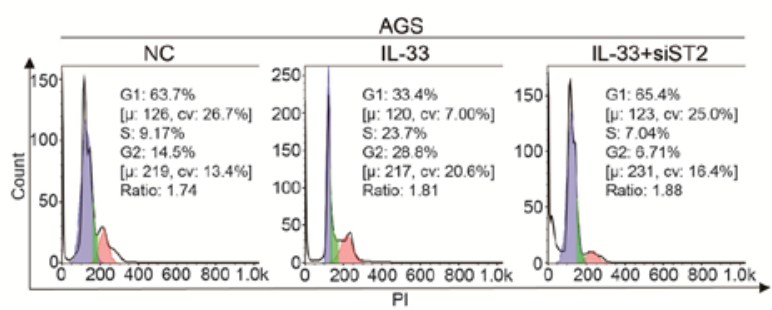

B

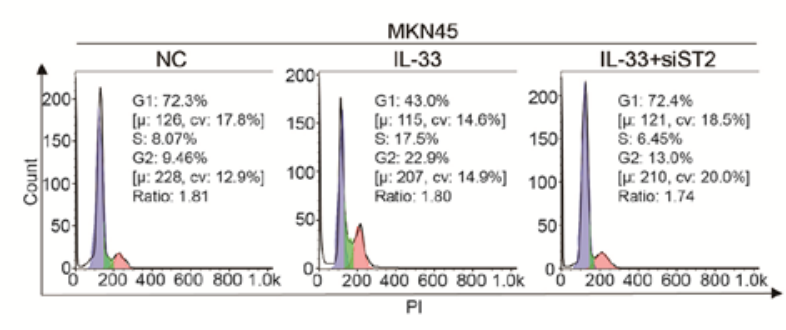

C

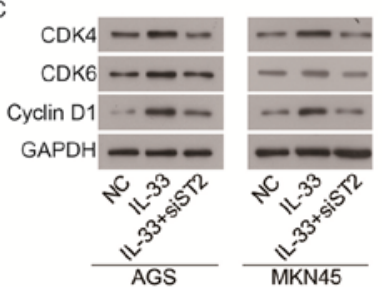

AGS

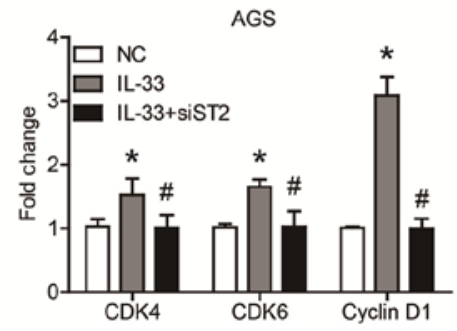

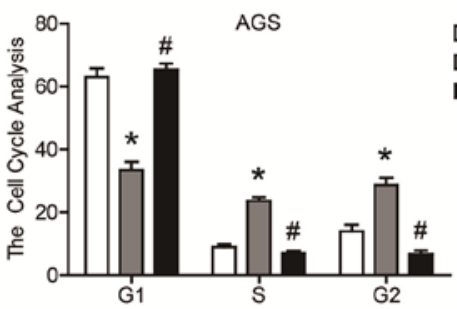

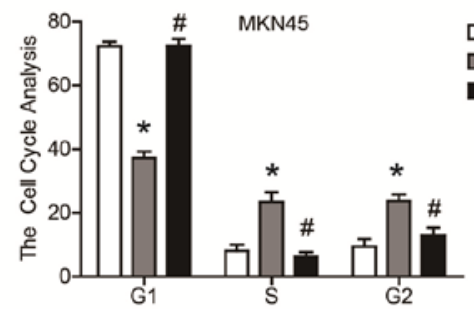

$\square$ NC

$\square$ IL-33

IL-33+SiST2

$\square$ NC

$\square$ IL-33

IL-33+siST2

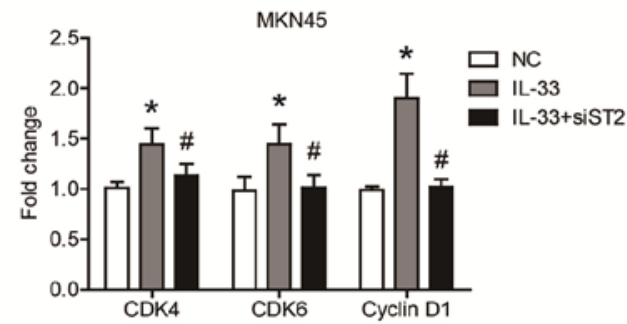

Figure 2. IL-33/ST2 axis promotes gastric cancer cell cycle progression. Cell cycle of (A) AGS and (B) MKN45 cells was detected by flow cytometry. (C) The protein expression of cell cycle-related proteins CDK4, CDK6 and Cyclin D1 were detected by western blotting. One-way ANOVA was used for comparison among multiple groups. All experiments were performed in triplicate. ${ }^{*} \mathrm{P}<0.05 \mathrm{IL}-33 \mathrm{vs}$. NC; ${ }^{\mathrm{P}}<0.05 \mathrm{IL}-33+\mathrm{siST} 2 \mathrm{vs}$. IL-33. GC, gastric cancer; NC, negative control; si-, small interfering RNA.

A

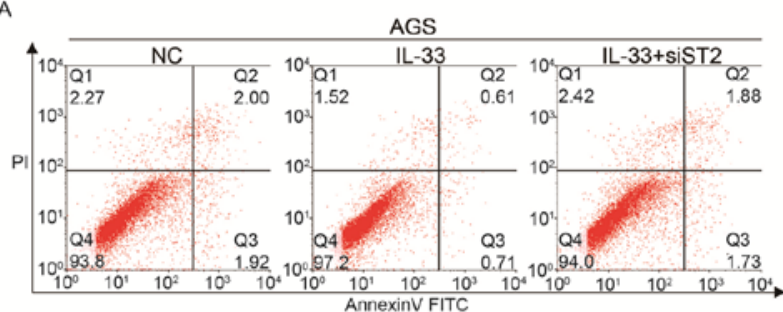

MKN45
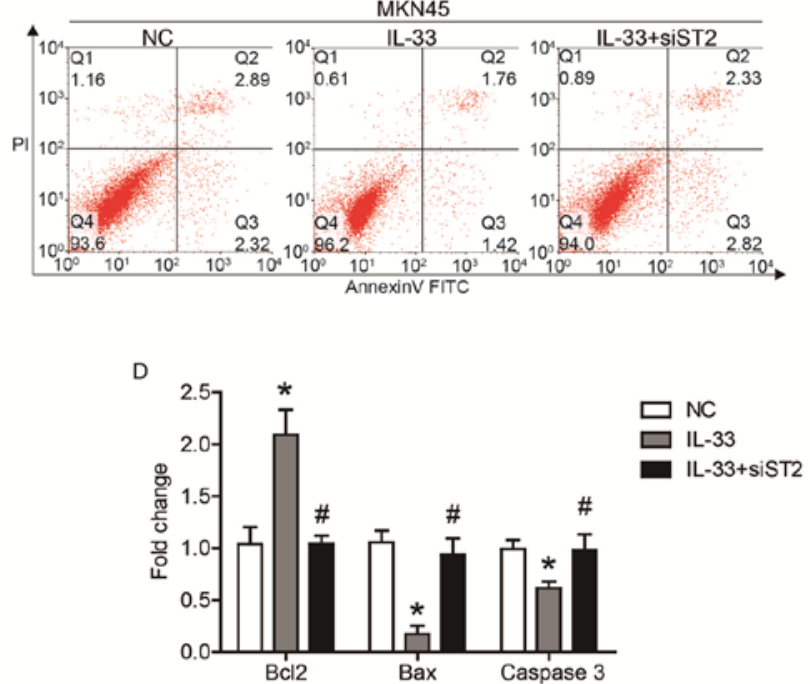

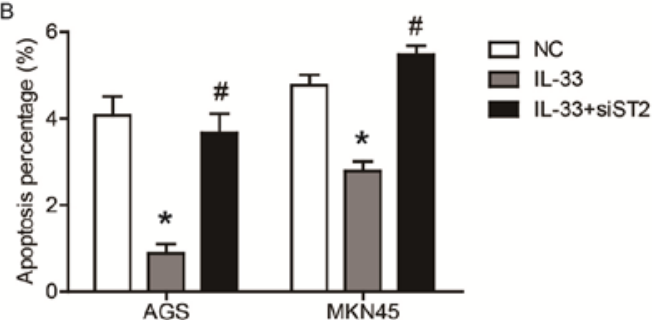

$\mathrm{C}$
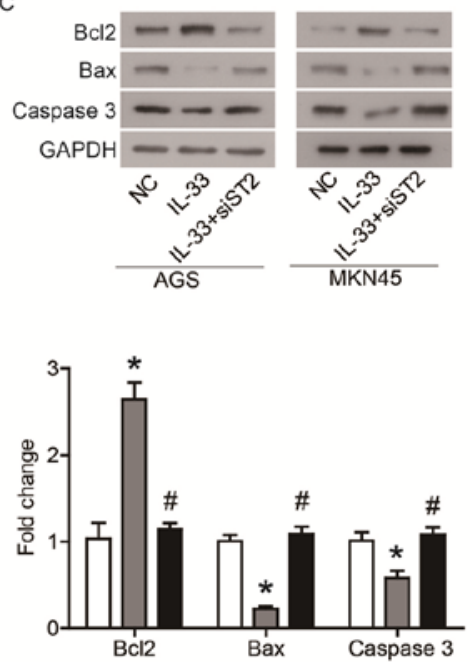

Figure 3. IL-33 inhibits gastric cancer cell apoptosis via the ST2 receptor. Apoptosis of (A) AGS and (B) MKN45 cells was detected by flow cytometry. (C and D) The protein expression levels of apoptosis-related proteins Bcl2, Bax and Caspase 3 were detected by western blotting. One-way ANOVA was used for comparison among multiple groups. All experiments were performed in triplicate. ${ }^{*} \mathrm{P}<0.05 \mathrm{IL}-33 \mathrm{vs}$. NC; ${ }^{*} \mathrm{P}<0.05 \mathrm{IL}-33+\mathrm{siST} 2 \mathrm{vs}$. IL-33. NC, negative control; si-, small interfering RNA. 
A

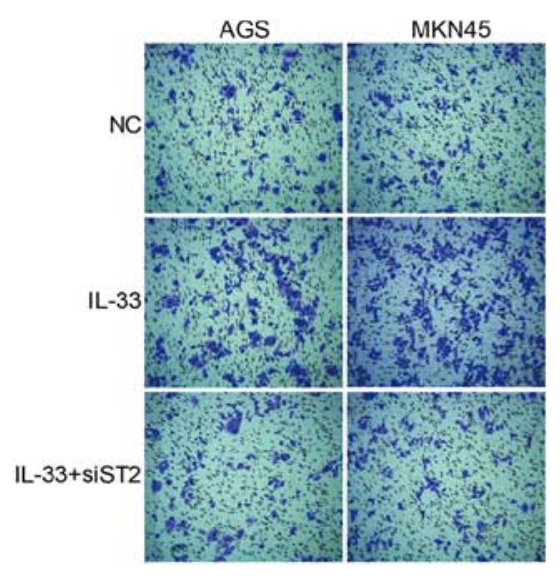

C

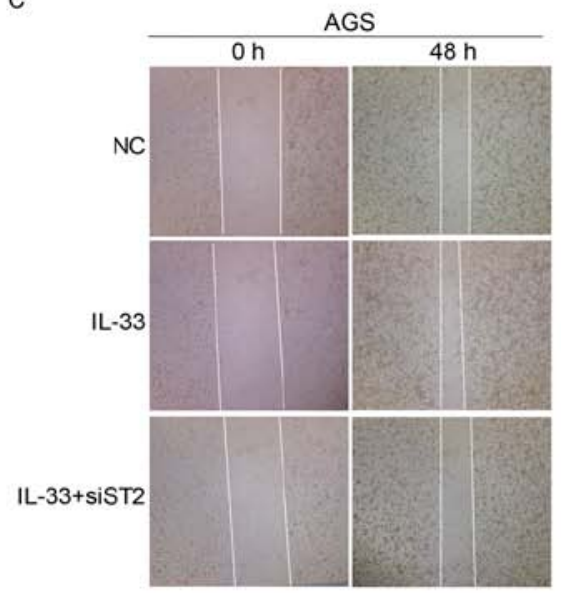

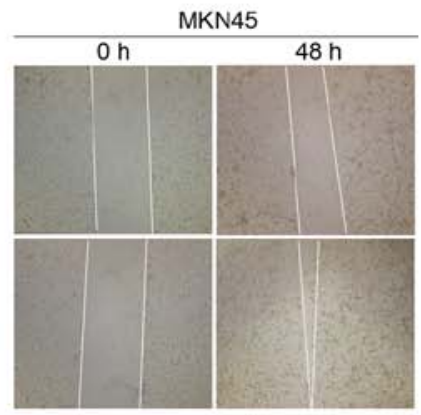

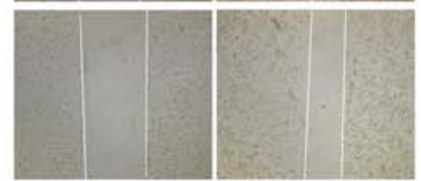

B

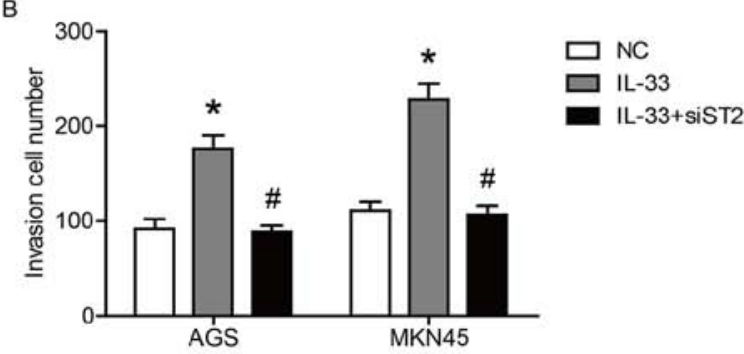

D

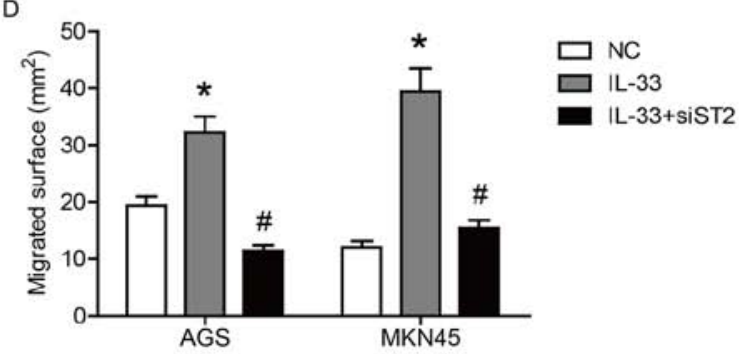

Figure 4. ST2 receptor contributes to IL-33-induced gastric cancer cell invasion and migration. (A and B) Cell invasion of AGS and MKN45 cells was detected by Transwell assays (magnification, x200). (C and D) Cell migration of AGS and MKN45 cells was detected by wound healing assays (magnification, x100). One-way ANOVA was used for comparison among multiple groups. All experiments were performed in triplicate. "P $<0.05 \mathrm{IL}-33 \mathrm{vs}$. NC; "P<0.05 IL-33+siST2 vs. IL-33. NC, negative control; si-, small interfering RNA.

A

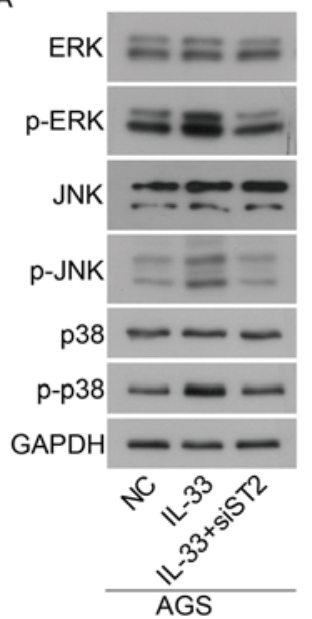

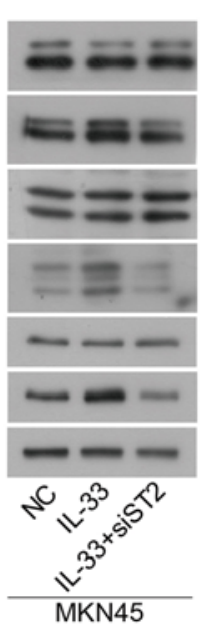

B

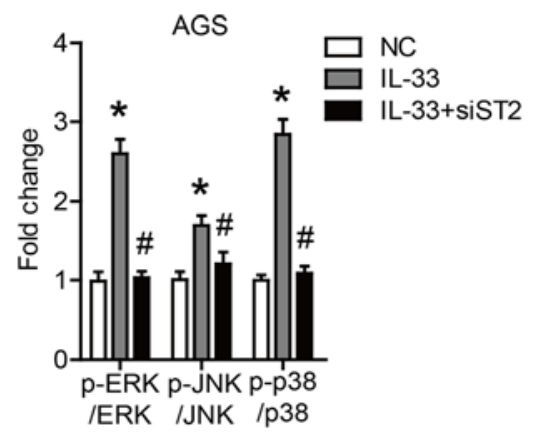

C

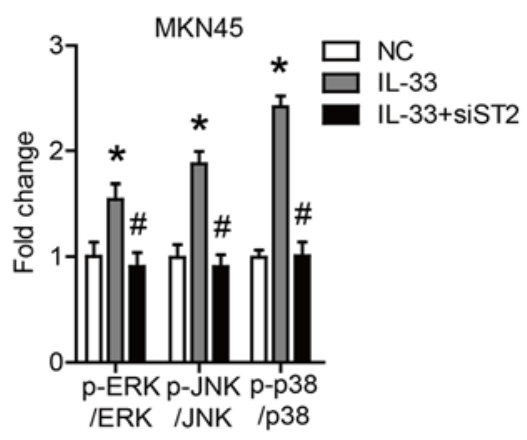

Figure 5. IL-33 induces activation of ERK1/2, JNK and p38 via ST2 receptor. (A-C) The protein expression and phosphorylation levels of ERK1/2, JNK and p38 were detected by western blotting. One-way ANOVA was used for comparison among multiple groups. All experiments were performed in triplicate. "P<0.05 IL-33 vs. NC; "P<0.05 IL-33+siST2 vs. IL-33. NC, negative control; si-, small interfering RNA; p-, phosphorylated.

MKN45 cells (Fig. 4A and B), whereas the invasive ability of both cells induced by IL-33 was significantly inhibited by the transfection of siST2 (Fig. 4A and B). In addition, the transfection of siST2 also reduced the migration of both cell lines stimulated by IL-33 (Fig. 4C and D). Taken together, these data indicated that IL-33 promoted the invasion and migration of GC cells through the ST2 receptor.
IL-33 induces the activation of ERK1/2, JNK and p38 via the ST2 receptor. Finally, the signaling pathways affected by IL-33 stimulation in GC cells were investigated. Western blotting showed that IL-33 stimulation increased the phosphorylation levels of ERK1/2, JNK and p38. Furthermore, it was found that the transfection of siST2 significantly inhibited the IL-33-induced activation of ERK1/2, JNK and p38 (Fig. 5A-C). 
These data suggested that IL-33 could induce the activation of ERK1/2, JNK and p38 through the ST2 receptor.

\section{Discussion}

In the present study, it was found that ST2 was expressed significantly higher in GC tissues, and IL-33 could induce ST2 expression in GC cells. The IL-33/ST2 axis promoted GC cell proliferation, cell cycle, apoptosis inhibition, and invasion and migration by inducing the activation of ERK1/2, JNK and p38.

The pro-inflammatory cytokine IL-33 is related to the occurrence and development of GC $(4,5)$. Overexpression of IL-33 has been observed in a number of types of tumors, including lung cancer and uterine leiomyoma $(18,19)$. However, little is known concerning the expression pattern of ST2 in tumor tissues. Although Bergis et al (3) demonstrated that serum ST2 levels in patients with GC are significantly higher than those in patients with gastritis or healthy volunteers. Moreover, ST2 serum levels may be significantly related to advanced or metastatic disease, as well as disease duration (3). The present study found that ST2 was significantly upregulated in GC tissues, although its expression level did not have a significant association with tumor size or pathological stage. Bai et al (20) suggested that the expression of ST2 protein in primary GC tissues is markedly lower than that in adjacent non-cancerous tissues, and may act as a tumor suppressor gene in GC, which is inconsistent with the present research. The controls in the studies of Bergis et al (3) and Bai et al (20) were adjacent tissues rather than normal tissues. Based on the complexity of the tumor microenvironment and the role of IL-33/ST2 axis in the para-cancerous mucosa, there may be individual differences in the ST2 expression in the para-cancerous tissues. The ST2 gene is widely expressed in different cell types, including immune and non-immune cells (21). Therefore, the source of soluble ST2 in serum is still uncertain. ST2 present in GC cells includes a full-length transmembrane form, a soluble secreted form, and other variants. In addition, the present study also found that IL-33 stimulation could induce ST2 expression.

In the present study, it was discovered that the IL-33/ST2 axis regulated the expression of cell cycle-associated proteins (CDK4, CDK6 and cyclin D1), thereby promoting cell cycle progression and ultimately affecting GC cell proliferation. In addition, it was also confirmed that the IL-33/ST2 axis could inhibit the apoptosis of GC cells. This seems to be consistent with research by Ye et al (4), which reported that IL-33 can protect GC cells from apoptosis induced by chemotherapy drugs. These data indicated that IL-33/ST2 is critical for the survival of GC cells.

The IL-33/ST2 axis is involved in the interaction between cancer cells and the tumor microenvironment. Retrospective studies of human GC have reported that tumor-adjacent, submucosal mast cells promote the growth of GC and participate in the formation of advanced disease and metastasis (22). Furthermore, a previous study suggested that mast cells recruit tumor-associated macrophages via the gastric cancer cell-derived IL-33/ST2 axis to promote tumor cell proliferation and angiogenesis (23). In fact, IL-33 is released by damaged epithelial cells as an endogenous danger signal that activates the innate immune response (9). IL-33 is reported to bind to a heterodimeric receptor complex composed of ST2 and IL-1R accessory proteins (24), and activate NK- $\kappa$ B (25), PI3K/AKT (26) and mitogen-activated proteins kinases (MAPKs) (27). Activated MAPK can transmit extracellular signals, and regulate cell growth, proliferation, differentiation, migration and apoptosis (27). The MAPK pathway is involved in extracellular signal-regulated kinases: ERK1/2, JNK and p38 kinase (27). In the present study, it was found that IL-33 could induce the activation of ERK1/2, JNK and p38 via the $\mathrm{ST} 2$ receptors in GC cells. Ye et al (4) demonstrated that JNK may be a key factor underlying the effect of IL-33 on GC cell chemotherapy-induced apoptosis. Furthermore, it was also reported that ERK1/2 activation is required for IL-33/ST2 axis-induced invasion and migration of GC cells (5).

In view of the role of the IL-33/ST2 axis in promoting the progression of $\mathrm{GC}$, therapeutic inhibition of signaling is a future direction for research. In addition, in order to clarify the molecular and cellular immune functions of IL-33 and ST2 in $\mathrm{GC}$, further studies are required in the local tumor environment.

In conclusion, it was found that IL-33/ST2 contributed to the malignant behaviors of GC cells by inducing the activation of ERK1/2, JNK and p38. This axis could become a potential effective target for the treatment of GC.

\section{Acknowledgements}

Not applicable.

\section{Funding}

The present study was supported by the Youth Program of National Natural Science Foundation of China (grant no. 81202839).

\section{Availability of data and materials}

The datasets used and/or analyzed during the current study are available from the corresponding author on reasonable request.

\section{Authors' contributions}

$\mathrm{NH}, \mathrm{XC}, \mathrm{WL}, \mathrm{CZ}, \mathrm{LL}$ and JL generated the hypothesis, designed and performed the experiments, analyzed the data, provided conceptual advice and technical expertise and edited the manuscript. NH conceived and supervised the study. All authors read and approved the final manuscript.

\section{Ethics approval and consent to participate}

The present study was approved by the Ethics Committee of The Affiliated Hospital of Shandong University of Traditional Chinese Medicine (Jinan, China). All patients provided written informed consent prior to enrollment in the study.

\section{Patient consent for publication}

Not applicable.

\section{Competing interests}

The authors declare that they have no competing interests. 


\section{References}

1. Nagini S: Carcinoma of the stomach: A review of epidemiology, pathogenesis, molecular genetics and chemoprevention. World $\mathbf{J}$ Gastrointest Oncol 4: 156-169, 2012.

2. Bertuccio P, Chatenoud L, Levi F, Praud D, Ferlay J, Negri E, Malvezzi M and La Vecchia C: Recent patterns in gastric cancer: A global overview. Int J Cancer 125: 666-673, 2009.

3. Bergis D, Kassis V and Radeke HH: High plasma sST2 levels in gastric cancer and their association with metastatic disease. Cancer Biomark 16: 117-125, 2016.

4. Ye XL, Zhao YR, Weng GB, Chen YC, Wei XN, Shao JP and Ji H: IL-33-induced JNK pathway activation confers gastric cancer chemotherapy resistance. Oncol Rep 33: 2746-2752, 2015.

5. Yu XX, Hu Z, Shen X, Dong LY, Zhou WZ and Hu WH: IL-33 promotes gastric cancer cell invasion and migration via ST2-ERK1/2 pathway. Dig Dis Sci 60: 1265-1272, 2015.

6. Ikeguchi M, Hatada T, Yamamoto M, Miyake T, Matsunaga T, Fukumoto Y, Yamada Y, Fukuda K, Saito H and Tatebe S: Serum interleukin-6 and -10 levels in patients with gastric cancer. Gastric Cancer 12: 95-100, 2009.

7. Kang JS, Bae SY, Kim HR, Kim YS, Kim DJ, Cho BJ, Yang HK, Hwang YI, Kim KJ, Park HS, et al: Interleukin-18 increases metastasis and immune escape of stomach cancer via the downregulation of CD70 and maintenance of CD44. Carcinogenesis 30: 1987-1996, 2009.

8. Haghshenas MR, Hosseini SV, Mahmoudi M, Saberi-Firozi M, Farjadian S and Ghaderi A: IL-18 serum level and IL-18 promoter gene polymorphism in Iranian patients with gastrointestinal cancers. J Gastroenterol Hepatol 24: 1119-1122, 2009.

9. Schmitz J, Owyang A, Oldham E, Song Y, Murphy E, McClanahan TK, Zurawski G, Moshrefi M, Qin J, Li X, et al: IL-33, an interleukin-1-like cytokine that signals via the IL-1 receptor-related protein ST2 and induces T helper type 2-associated cytokines. Immunity 23: 479-490, 2005.

10. Mirchandani AS, Salmond RJ and Liew FY: Interleukin-33 and the function of innate lymphoid cells. Trends Immunol 33: 389-396, 2012.

11. Liu J, Shen JX, Hu JL, Huang WH and Zhang GJ: Significance of interleukin-33 and its related cytokines in patients with breast cancers. Front Immunol 5: 141, 2014.

12. Mohran ZY, Ali-Eldin FA and Abdel Aal HA: Serum interleukin-18: Does it have a role in the diagnosis of hepatitis $C$ virus related hepatocellular carcinoma? Arab J Gastroenterol 12: 29-33, 2011.

13. Musolino C, Allegra A, Profita M, Alonci A, Saitta S, Russo S, Bonanno A, Innao V and Gangemi S: Reduced IL-33 plasma levels in multiple myeloma patients are associated with more advanced stage of disease. Br J Haematol 160: 709-710, 2013.

14. Sun P, Ben Q, Tu S, Dong W, Qi X and Wu Y: Serum interleukin-33 levels in patients with gastric cancer. Dig Dis Sci 56: 3596-3601, 2011.
15. Hu W, Wu C, Li X, Zheng Z, Xie Q, Deng X, Jiang J and Wu C: Serum IL-33 level is a predictor of progression-free survival after chemotherapy. Oncotarget 8: 35116-35123, 2017.

16. Hu W, Li X, Li Q, Tan Y, Xu B, Xie Q, Deng X, Lu B, Jiang J and Wu C: Interleukin-33 expression does not correlate with survival of gastric cancer patients. Pathol Oncol Res 23: 615-619, 2017.

17. Livak JK and Schmittgen TD: Analysis of relative gene expression data using real-time quantitative PCR and the 2(-Delta Delta C(T)) method. Methods 25: 402-408, 2001.

18. Santulli P, Even M, Chouzenoux S, Millischer AE, Borghese B, de Ziegler D, Batteux F and Chapron C: Profibrotic interleukin-33 is correlated with uterine leiomyoma tumour burden. Hum Reprod 28: 2126-2133, 2013.

19. Zhang P, Liu XK, Chu Z, Ye JC, Li KL, Zhuang WL, Yang DJ and Jiang YF: Detection of interleukin-33 in serum and carcinoma tissue from patients with hepatocellular carcinoma and its clinical implications. J Int Med Res 40: 1654-1661, 2012.

20. Bai F, Ba F, You Y, Feng Y, Tao W, Wu C, Jiu M and Nie Y: Decreased ST2 expression is associated with gastric cancer progression and pathogenesis. Oncol Lett 17: 5761-5767, 2019.

21. Trajkovic V, Sweet MJ and Xu D: T1/ST2-an IL-1 receptor-like modulator of immune responses. Cytokine Growth Factor Rev 15: 87-95, 2004

22. Zhao Y, Wu K, Cai K, Zhai R, Tao K, Wang G and Wang J: Increased numbers of gastric-infiltrating mast cells and regulatory $\mathrm{T}$ cells are associated with tumor stage in gastric adenocarcinoma patients. Oncol Lett 4: 755-758, 2012.

23. Eissmann MF, Dijkstra C, Jarnicki A, Phesse T, Brunnberg J, Poh AR, Etemadi N, Tsantikos E, Thiem S, Huntington ND, et al: IL-33-mediated mast cell activation promotes gastric cancer through macrophage mobilization. Nat Commun 10: 2735, 2019.

24. Chackerian AA, Oldham ER, Murphy EE, Schmitz J, Pflanz S and Kastelein RA: IL-1 receptor accessory protein and ST2 comprise the IL-33 receptor complex. J Immunol 179: 2551-2555, 2007.

25. Wu Y, Wang F, Fan L, Zhang W, Wang T, Du Y and Bai X: Baicalin alleviates atherosclerosis by relieving oxidative stress and inflammatory responses via inactivating the NF- $\mathrm{KB}$ and p38 MAPK signaling pathways. Biomed Pharmacother 97: $1673-1679,2018$.

26. Jovanovic IP, Pejnovic NN, Radosavljevic GD, Arsenijevic NN and Lukic ML: IL-33/ST2 axis in innate and acquired immunity to tumors. Oncoimmunology 1: 229-231, 2012.

27. Sui X, Kong N, Ye L, Han W, Zhou J, Zhang Q, He C and Pan H: p38 and JNK MAPK pathways control the balance of apoptosis and autophagy in response to chemotherapeutic agents. Cancer Lett 344: 174-179, 2014.

This work is licensed under a Creative Commons Attribution-NonCommercial-NoDerivatives 4.0 International (CC BY-NC-ND 4.0) License. 